\title{
High Speed Traveling Wave Electrooptic Intensity Modulator with a Doped PIN Semiconductor Junction
}

\author{
G.A. Vawter, V.M. Hietala, J.R. Wendt, B.A. Fuchs, M. Hafich, \\ M. Housel, M. Armendariz and C.T. Sullivan
}

Sandia National Laboratories

P.O. Box 5800, MS 0603

$C_{i}=$

$\lim _{i \rightarrow \infty} \& 40$

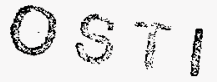

Albuquerque, NM 87185-0603

ph. (505) 844-9004; fax 844-8985

\begin{abstract}
A high-electrooptic-efficiency Mach-Zehnder intensity modulator is demonstrated with a bandwidth exceeding $40 \mathrm{GHz}$. The $1 \mathrm{~mm}$-long modulator has a switching voltage comparable to undoped semiconductor designs of much greater length.

This work was supported by the US/DOE under contract no. DE-AC04-94AL85000.

\section{DISCLAIMER}

This report was prepared as an account of work sponsored by an agency of the United States Government. Neither the United States Government nor any agency thereof, nor any of their employees, makes any warranty, express or implied, or assumes any legal liability or responsibility for the accuracy, completeness, or usefulness of any information, apparatus, product, or process disclosed, or represents that its use would not infringe privately owned rights. Reference herein to any specific commercial product, process, or service by trade name, trademark, manufacturer, or otherwise does not necessarily constitute or imply its endorsement, recommendation, or favoring by the United States Government or any agency thereof. The views and opinions of authors expressed herein do not necessarily state or reflect those of the United States Government or any agency thereof.
\end{abstract}




\title{
High Speed Traveling Wave Electrooptic Intensity Modulator with a Doped PIN Semiconductor Junction
}

\author{
G.A. Vawter, V.M. Hietala, J.R. Wendt, B.A. Fuchs, M. Hafich, \\ M. Housel, M. Armendariz and C.T. Sullivan \\ Sandia National Laboratories, P.O. Box 5800, MS 0603 \\ Albuquerque, NM 87185-0603, ph. (505) 844-9004; fax 844-8985
}

\begin{abstract}
Extremely fast modulation response of optical phase delay in a waveguide modulator is required for photonic integrated circuits (PICs) to operate with mm-wave signals. Single phase modulators, paired phase modulators in a Mach-Zehnder interferometer, or more complex arrangements can be used for mm-wave modulation of light in either phase, amplitude, or frequency. Standard lumped-element devices are bandwidth limited by the RC time-constant of the structure. Distributed, or traveling-wave designs have been developed to surpass the RC limit. With distributed structures the bandwidth limit is determined by loss of phase synchronism between the optical and RF wavefronts within the length of the device. The generally different propagation constants of the optical and RF waves leads to a limiting lengthbandwidth product in the modulation response. In the limit of zero velocity mismatch the modulation bandwidth is then limited by RF loss in the transmission line. Velocity matching in undoped or low-doped semiconductor optoelectronic modulators typically involves use of a slow-wave transmission line electrode structure. Several successful techniques have been developed[1-2], but undoped structures offer low electrooptic efficiency, resulting in undesirably large devices. We disclose a device using doped semiconductor structures to increase efficiency in a traveling-wave modulator. This new design is demonstrated to have a bandwidth greater than $40 \mathrm{GHz}$ in a Mach-Zehnder intensity modulator operating at $1.32 \mu \mathrm{m}$ wavelength while maintaining $\mathrm{V}_{\pi}=10 \mathrm{~V}$ with a phase modulator section only $1 \mathrm{~mm}$-long.
\end{abstract}

Electrooptic efficiency can be dramatically increased through the appropriate use of doping in a semiconductor optical waveguide. A $p-i-n$ junction centered on the optical mode of the waveguide concentrates the applied electric field within the optical mode, yielding higher optical phase shift per unit applied voltage compared to undoped waveguides. The improved efficiency permits the use of shorter modulators for a given applied voltage. Use of doped waveguides does increase the optical loss but the overall loss of the device can be similar to an undoped design due the reduced length.[3]

Figure (1) shows the cross-section of the optical phase modulator used in the high-speed Mach-Zehnder. The waveguide comprises an (Al,Ga)As cutoff-mesa rib optical waveguide.[4] A $p-i-n$ junction with a $0.6 \mu \mathrm{m}$ undoped thickness is centered on the $0.2 \mu \mathrm{m}$ thick GaAs waveguide core. The upper waveguide rib is $2 \mu \mathrm{m}$ wide, the waveguide mesa is $10 \mu \mathrm{m}$ wide. The microwave transmission line comprises a $14 \mu \mathrm{m}$-wide Au strip balanced on the waveguide and ground-plane metalization contacting a continuous $\mathrm{n}^{+} \mathrm{GaAs}$ layer placed below the etched mesa. Vertical and horizontal spacing between the ground metalization and the center strip, is used to control the microwave phase velocity. The intrinsic region thickness also has a strong influence on the microwave phase velocity. However, this thickness is kept at a practical minimum in order to maintain the desired high optical modulation efficiency.

A quasi-TEM transmission-line model was used to predict the transmission line characteristics and phase modulation response versus frequency. At $30 \mathrm{GHz}$, the microwave index, loss and characteristic impedance are calculated to be $3.31,2 \mathrm{~dB} / \mathrm{mm}$ and $(22-0.56 \mathrm{j})$ Ohms respectively. The microwave index is well matched with the optical modal index of 3.3134 at the $1.32 \mu \mathrm{m}$ wavelength calculated using a two-dimensional finite difference technique. Using theoretical transmission-line losses, ideal impedance matching at the source and load and a fixed electrooptic efficiency, the model indicates that a $1 \mathrm{~mm}$-long device would have a bandwidth 
between 50 and $100 \mathrm{GHz}$ (Figure 2). This model is expected to overestimate the bandwidth to some extent as the RF loss is known to increase with frequency.

Mach-Zehnder intensity modulators were fabricated using epitaxial layers grown by molecular-beam-epitaxy. All etching was by chlorine reactive ion beam etching. A PMGI-based air-bridge metal plating technique was used to create the central metal strip balanced on the waveguide rib. The transmission line was terminated at both ends with pads placed directly on the semi-insulating substrate for Cascade microprobes. Final cleaved devices were $3 \mathrm{~mm}$ in length including the $1 \mathrm{~mm}$-long phase modulator, input and output waveguides and optical power combiners/splitters occupied the remaining length. The two arms of the Mach-Zehnder were driven asymmetrically with one arm held to ground potential and the other comprising the high-speed phase modulator.

Small signal electrical response was measured to $40 \mathrm{GHz}$ using an amplitude modulated microwave signal[5] and a DC-bias of $-10 \mathrm{~V}$. As seen in Figure (3), the response is fairly flat out to $20 \mathrm{GHz}$ with a peak at $30 \mathrm{GHz}$. The device does not show a $-3 \mathrm{~dB}$ roll-off within the 40 Ghz measured frequency range. The peak at $30 \mathrm{GHz}$ is most likely a resonance caused by the use of $50 \mathrm{Ohm}$ probes, cables and output termination on the $22 \mathrm{Ohm}$ transmission-line structure. This impedance mismatch was not included in the model of Figure (2). Use of proper impedance-matching techniques should flatten the resonance, providing a more uniform frequency response. S-parameter measurements up to $20 \mathrm{GHz}$ were performed using a network analyzer. From this data, the measured RF loss of a $1 \mathrm{~mm}$-long device is seen to increase monotonically from 1.3 to $2.4 \mathrm{~dB} / \mathrm{mm}$ between 10 and $20 \mathrm{GHz}$.

In conclusion, a Mach-Zehnder intensity modulator at $1.32 \mu \mathrm{m}$ wavelength has been demonstrated with a modulation bandwidth greater than $40 \mathrm{Ghz}$. The device uses a doped $p-i-n$ semiconductor junction for high electrooptic modulation efficiency and small overall size. The 1 mm-long modulator section has a $\mathrm{V}_{\pi}=10 \mathrm{~V}$, comparable to undoped semiconductor designs of much greater length.

This work was supported by the United States Department of Energy under Contract DEAC04-94AL8500.

\section{References:}

[1] R.G. Walker, Proceedings of the IEEE Lasers and Electrooptics Society 1995 Annual Meeting, Vol. 1, pp. 120121, San Fransisco, CA, Oct. 30-Nov. 2, 1995.

[2] R. Spickermann, S. Sakamoto, M. Peters and N. Dagli, Proceedings of the IEEE Lasers and Electrooptics Society 1995 Annual Meeting, Vol. 1, pp. 118-119, San Fransisco, CA, Oct. 30-Nov. 2, 1995.

[3] G.A. Vawter, V.M. Hietala, S.H. Kravitz, M.G. Armendariz, Proceedings of the International 1994 IEEE MTT-S Topical meeting on Optical Microwave Interactions, pp. 3-6, Ile de France, France, Nov. 21-23, 1994.

[4] G.A. Vawter, R.E. Smith, B. Fuchs, J.R. Wendt, M. Hafich, G.R. Hadley, Proceedings of the IEEE Lasers and Electrooptics Society 1995 Annual Meeting, Vol. 1, pp. 137-138, San Fransisco, CA, Oct. 30-Nov. 2, 1995.

[5] S. Uehara, Applied Optics, Vol. 17, No. 1, pp. 68-71, 1978 


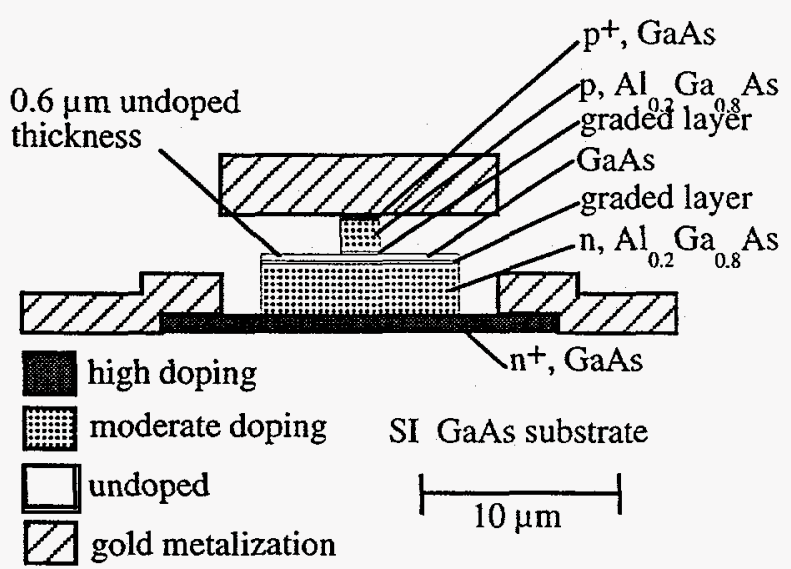

Figure 1: Cross-section view of the travelingwave phased modulator with doped $p-i-n$ waveguide design. Figure is drawn approximatly to scale. The outer Au groundplane metalizations extend beyond the edges of the drawing.

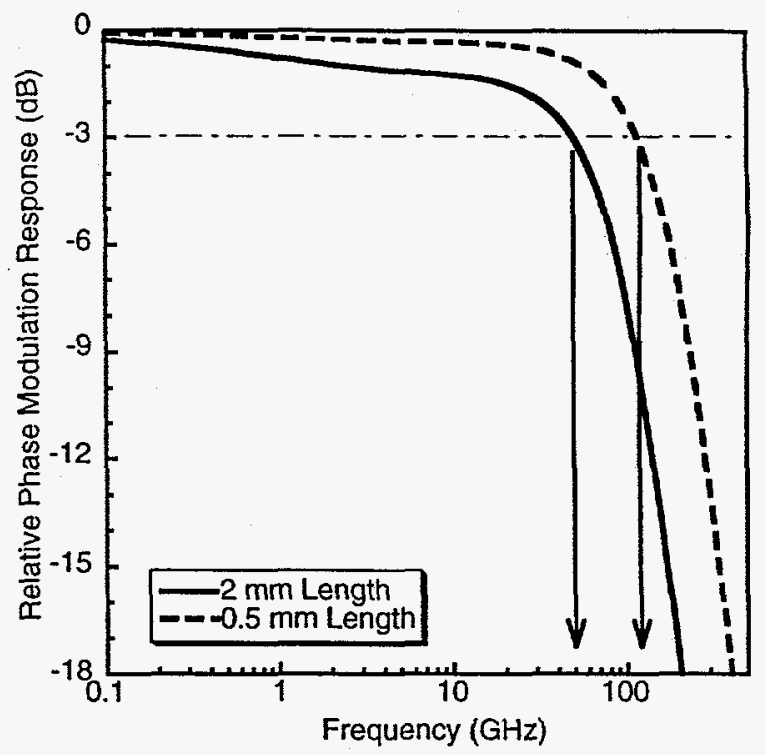

Figure 2. Theoretical traveling-wave phase modulator response as function of frequency. Dashed line is $0.5 \mathrm{~mm}$ long device. Solid line is $2 \mathrm{~mm}$ long device.

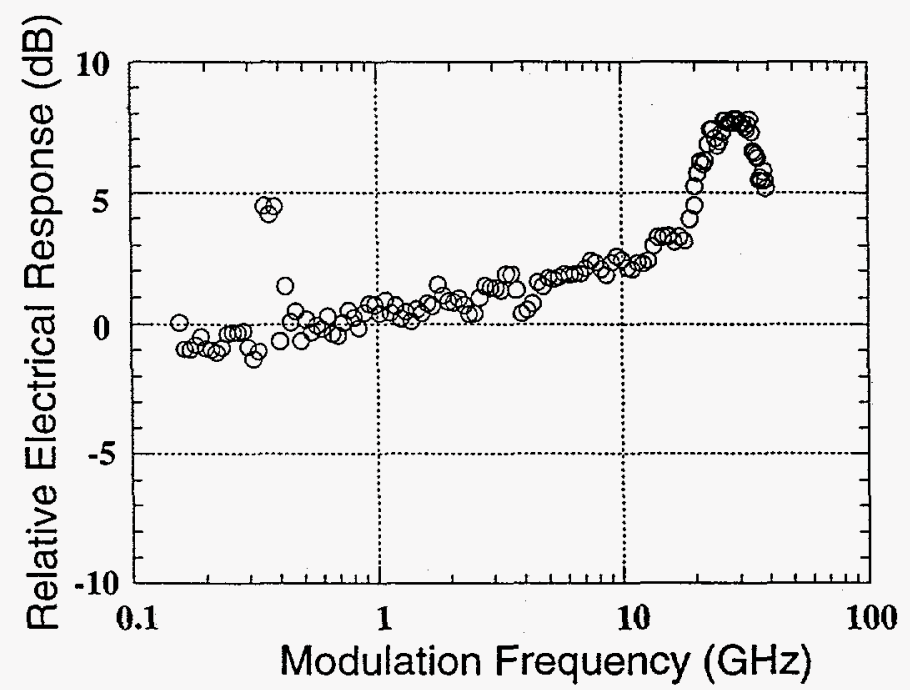

Figure 3: Relative small-signal electrical response of a Mach-Zehnder intensity modulator employing a $1 \mathrm{~mm}$-long phase modulator of the design in Figure (1). 


\section{DISCLAMMIER}

Portions of this document may be illegible in electronic image products. Images are produced from the best available original document. 